\title{
IMPROVEMENT OF COOLING SYSTEM OF ELECTRICAL EQUIPMENT USING SIMULATION OF AIRFLOW AND HEAT TRANSFER
}

\author{
Janis Galins, Aigars Laizans, Ainars Galins \\ Latvia University of Life Sciences and Technologies, Latvia \\ janis.galins@1lu.lv, aigars.laizans@1lu.lv, ainars.galins@1lu.lv
}

\begin{abstract}
The research is devoted to the results of air flow and heat transfer simulation application in the design of compact electrical equipment with the aim of increasing the efficiency of the cooling system. The design of electrical equipment involves not only the creation of an ergonomic, attractive shape, but also to the solutions to overheating problems. Excessive heat is to be emitted to the environment, and for small size devices the necessity is the properly designed accelerated air flow through the system. In order to find out the high risk areas in the device, which are under the risk of substantial overheating due to inadequate air flow intensity, the simulation model of airflow and heat transfer processes for the particular device was developed in the Solidworks software. The experimental device with the axial fan used for air flow supply to the heated areas was made to evaluate the temperature and air flow velocity. Comparison of the experimental and simulation results showed that the simulated air flow speed is describing the real situation with the experimental flow measurements in the device with $91 \%$ coincidence. Temperature measurements differed from the simulations only by $7 \%$ in some areas, but the distribution pattern remained. Studies of the air flow trajectory and speed revealed the tendency of negative intercorrelation of the air flow rate and the surface temperature.
\end{abstract}

Keywords: cooling system, heat modelling, air cooling, heat transfer.

\section{Introduction}

Reduction of design and production costs is important, including the costs of testing prototypes, while developing and manufacturing new products, whilst increasing the quality of products. Modern $3 \mathrm{D}$ design software allows testing of various parameters during the design of a digital model, for example, determination of part and assembled mechanism strength parameters, determination of kinematic and dynamic parameters during movement of the mechanism, simulation of fluid flow and temperature dynamics, imitation of the plastic moulding process, etc. Simulation allows to evaluate the design adequacy - the device performance, operation quality and safety, resulting in cost reduction and accelerated product launch into the market. Cost reduction comes also from the minimal number of physical prototypes produced that are required before starting mass production.

The world experience of simulation use in cooling is rather extensive and shows extremely good results. The Flow Simulation Tool from Solidworks software used in this research performs gas or fluid flow simulation by determining the fluid flow rates and trajectories in various locations of the test object, the heat transfer, and the fluid forces acting on the structure. The example of fast and high quality simulation is the membrane cooling development [1]. Using spatial design software and flow simulation capabilities, researchers have succeeded in improving the cooling quality by $28 \%$. This was achieved by optimizing the angle, at which cold air enters the membrane.

Flow simulations are also carried out in wind tunnel studies to increase the rotational speed of the rotor. The faster the wind generator rotates, the more alternative energy is produced. Improvements were made by changing the rotor's geometric parameters [2;3]. The efficiency of the cooling system can significantly increase by optimizing the location of the cooling components and the shape of the housing.

The object for this study is the ozone generator intended for indoor use. Ozone generators use heat dissipating components, therefore, to create a good design model of the equipment, flow and heat transfer simulations are needed to determine the optimal location of hot components in the housing. The main parts of the ozone generator are shown in Fig. 1.

Insulating material strips are used to mount the corona discharge plates into the housing close to the outlet of the ozone generator to make it easier to replace defective elements. The front part of the voltage multiplier is lifted up to improve the cooling of the heat sink as seen in Fig 1. The aim of the study is to increase the efficiency of the cooling system for electrical equipment by using heat transfer and air flow simulations. 


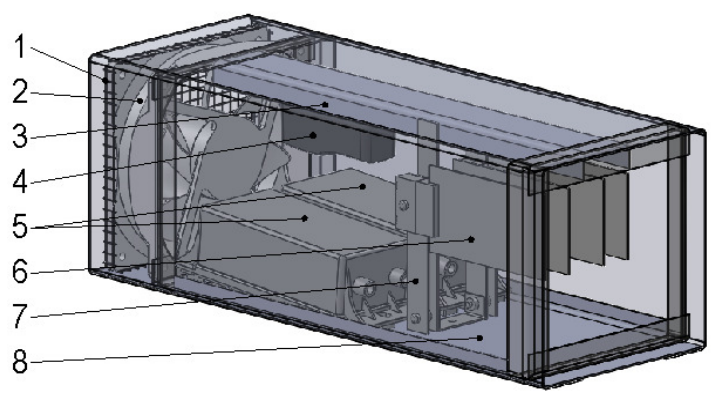

Fig. 1. Ozone generator structure: 1 - fan guard; 2 - Foxconn PV123812DSPF fan; 3 - frame; 4 - power supply adapter; 5 - voltage multipliers; 6 - ceramic corona discharge plates; 7 - insulating material strip; 8 - housing

\section{Materials and methods}

Computational fluid dynamics (CFD) and heat transfer simulations were performed in the Solidworks software. Totally 6 different ozone producing corona discharge ceramic plate displacement configurations have been created in order to simulate the airflow and heat transfer. The plate displacement and variable parameters are presented in Fig. 2.

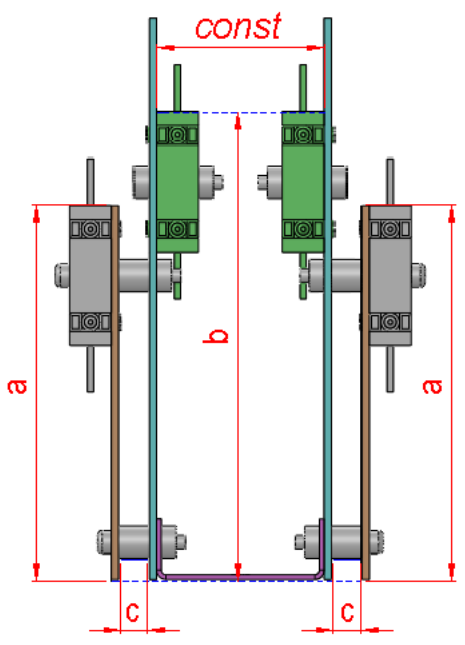

Fig. 2. Corona discharge ceramic plate placement and variables defined

The applied values of plate displacement variable parameters are presented in Table 1.

Table 1

\section{Variable placement size values used for configurations by CFD and heat transfer simulations}

\begin{tabular}{|c|c|c|c|}
\hline \multirow{2}{*}{$\begin{array}{c}\text { Configuration } \\
\text { No. }\end{array}$} & a & bength, mm & c \\
\cline { 2 - 4 } & 80 & 80 & 6.4 \\
\hline 1 & 100 & 100 & 6.4 \\
\hline 2 & 90 & 90 & 6.4 \\
\hline 3 & 100 & 100 & 9.6 \\
\hline 4 & 80 & 100 & 6.4 \\
\hline 5 & 100 & 80 & 6.4 \\
\hline 6 &
\end{tabular}

The experimental device - ozone generator (as presented in Fig.1) with the axial fan used for air flow supply to the heated areas was made to evaluate the temperature and air flow velocity. Various experimental measurements were performed and the obtained results are further used for simulation input data.

Digital anemometer GM816A was used for air velocity measurements with measuring the range from 0 to $30 \mathrm{~m} \cdot \mathrm{s}^{-1}$, resolution $0.1 \mathrm{~m} \cdot \mathrm{s}^{-1}$ with accuracy $\pm 5 \%$ [4]. 
Digital calliper Mitutoyo 500-161-20 was used to measure the shape of the rotor wings. Provided measuring range is from 0 to $150 \mathrm{~mm}$ with accuracy $\pm 0.02 \mathrm{~mm}$ [5]. The digital fan model was developed according to the measurements of calliper.

Three-phase energy meter Carlo Gavazzi EM21 with voltage and current measurement accuracy $\pm 0.5 \%$ was used to measure the electrical power, current, and voltage [6]. Power measurements are made for 2 voltage multipliers and 4 corona discharge ceramic plates. About $90 \%$ of the power supplied to the generator is being utilized to produce light, sound and primary heat [7].

The tachometer TM- 4010 with accuracy $\pm 0.01 \%$ was used to measure the fan speed by the contactless measuring method with reflective tape [8]. The rotation speed measurements of the fan were made at a distance of $30 \mathrm{~cm}$ from the rotor, so as not to affect the cross-sectional area of the flow. The reflecting tape was attached to the middle of the fan rotor during the measurement. Rotation speed of the fan is shown in Table 2. The measurement values for the wattmeter, tachometer and anemometer fluctuated, so the smallest and largest value of the reading is recorded and the average value is calculated.

For each ceramic plate, the maximum heating temperature was measured using the infrared thermometer 42510A. Before starting the measurement, the thermal emission of the infrared thermometer was set according to the ceramics: $\varepsilon=0.92$. Accuracy depends on the temperature. The infra-red thermometer has an accuracy of $\pm 2.5^{\circ} \mathrm{C}$ between $-2{ }^{\circ} \mathrm{C}$ to $94{ }^{\circ} \mathrm{C}$ in the measuring range used [9].

The measured electric power for 2 voltage multipliers and 4 corona discharge ceramic plates fluctuated from 124 to $130 \mathrm{~W}$. The average value was $127 \mathrm{~W}$. About $90 \%$ or $114 \mathrm{~W}$ are consumed for light, sound and primary heat production. This power was used for heat transfer simulations as shown in Table 2. The measured fan rotation speed value was $3080 \mathrm{rpm}$. Room temperature was approximately $20^{\circ} \mathrm{C}$ or $293.2 \mathrm{~K}$. Other input data are selected according to the model equipment.

Table 2

Input data for CFD and heat transfer simulations

\begin{tabular}{|c|c|c|}
\hline Parameter & Value & Unit \\
\hline Rotation speed of the fan & 3080 & $\mathrm{rpm}$ \\
\hline Gravity in y axis direction & -9.81 & $\mathrm{~m} \cdot \mathrm{s}^{-2} ;$ \\
\hline Atmospheric pressure & 101325 & $\mathrm{~Pa}$ \\
\hline Ambient temperature & 293.2 & $\mathrm{~K}$ \\
\hline Heat generation rate for ceramic corona discharge plates & 60 & $\mathrm{~W}$ \\
\hline Heat generation rate for two voltage multipliers & 54 & $\mathrm{~W}$ \\
\hline Fluid type & \multicolumn{2}{|c|}{ Air } \\
\hline
\end{tabular}

The simulation results are significantly influenced by the selected solid materials, because each of them has a different thermal conductivity. The selected materials are shown in Table 3.

Table 3

Solid materials used for CFD and heat transfer simulations

\begin{tabular}{|c|c|c|}
\hline Part & Material & $\begin{array}{c}\text { Thermal conductivity, } \\
\mathbf{W} \cdot(\mathbf{m} \cdot \mathbf{K})^{-1}[\mathbf{1 0}]\end{array}$ \\
\hline Voltage multiplier cover & Polytetrafluoroethylene (PTFE) & 0.25 \\
\hline Voltage multiplier heatsink & Aluminium 5052 & $\sim 77$ (depends on temperature) \\
\hline $\begin{array}{c}\text { Ceramic corona discharge } \\
\text { plates }\end{array}$ & Alumina 99.9\% & 30 \\
\hline Housing & 1.4301 (X5CrNi18-10), AISI 304 & 16 \\
\hline $\begin{array}{c}\text { Insulating material strips } \\
\text { (textolite) for mounting } \\
\text { ceramic plates }\end{array}$ & $\begin{array}{c}\text { Material with similar thermal } \\
\text { conductivity (Laminate FR4) }\end{array}$ & 0.3 \\
\hline
\end{tabular}

\section{Results and discussion}

The corona discharge plate temperatures from heat transfer simulations are shown in Fig. 3. 


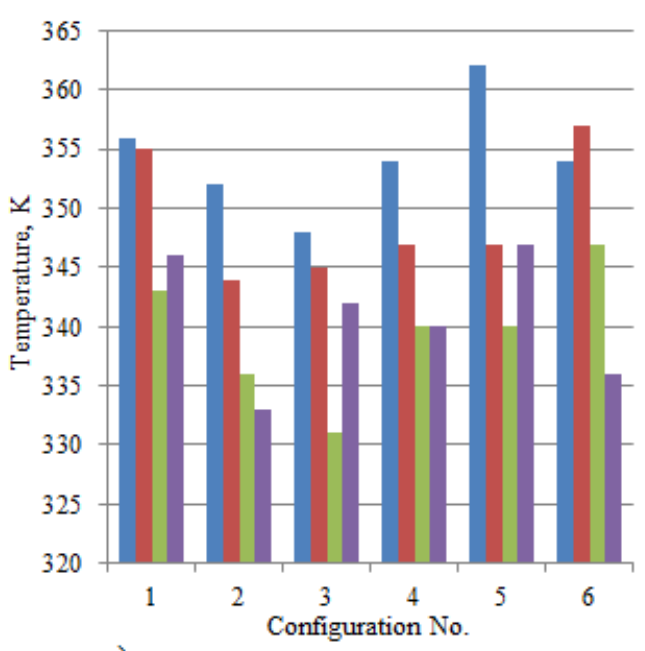

a)

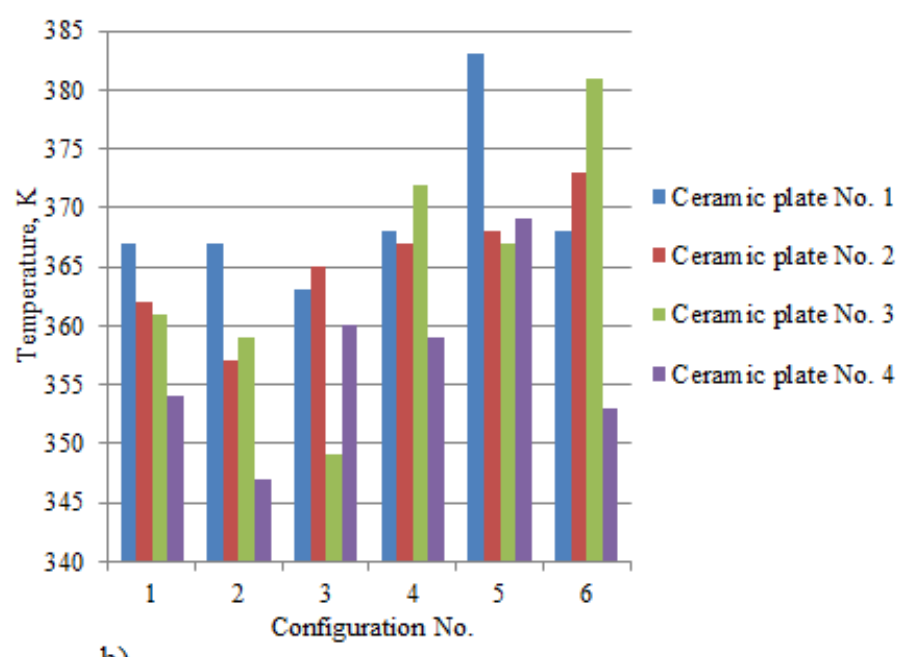

b)

Fig. 3. Temperature of corona discharge plates for different configurations:

$\mathrm{a}$ - average temperature; $\mathrm{b}$ - maximum temperature

Analysis of the data acquired from 6 configurations (as shown in Fig. 3) allowed to conclude that the problem zone is the 1 st and 2 nd plates with highest average temperatures. The extreme results (the highest temperature reached - maximum) were gained from the 5th and 6th configuration. The lowest temperatures are observed for configuration No. 3. As the aim of the cooling system is to reduce the cooling irregularity, avoiding high maximum temperature values, therefore the experimental equipment was created according to configuration No. 3 .

The distribution of temperature over the ceramic plates for configuration No. 3 is shown in Fig. 4 but the air flow velocity is depicted in Fig. 5.
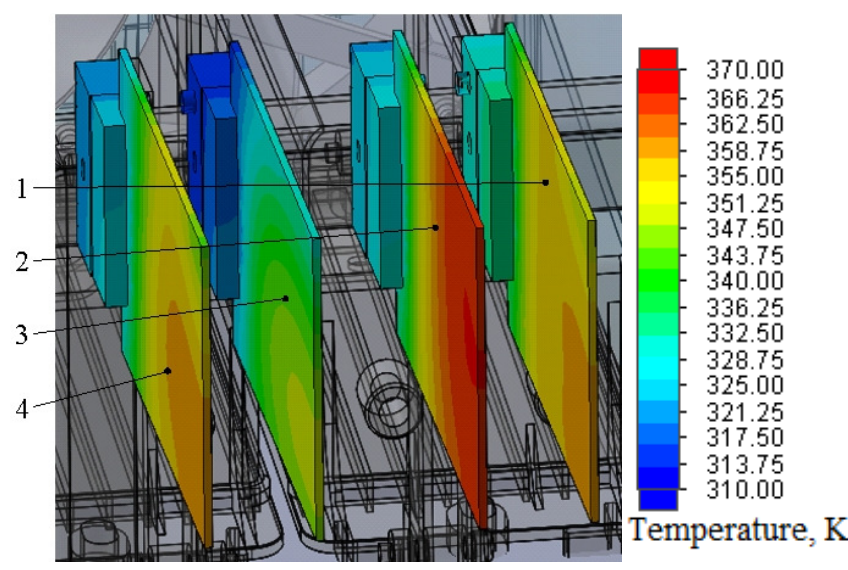

\section{Fig. 4. Corona discharge plate temperature for} configuration No. 3

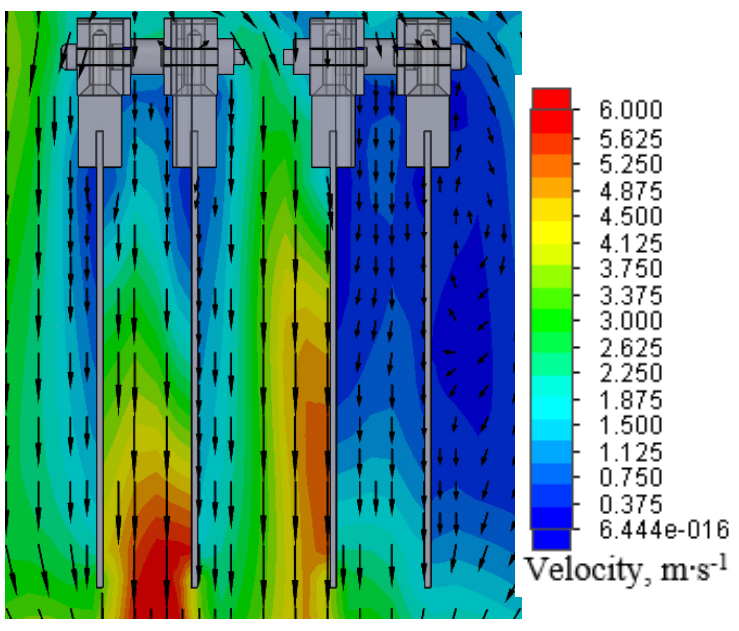

Fig. 5. Air flow velocity simulation for configuration No. 3

The first and second ceramic plates heat up the most because the air flow rates between the plates are small, as seen in Fig. 5. Air flow trajectories greatly affect the cooling irregularity.

The corona discharger placement optimization includes not only heat transfer as the optimization aim, but the high voltage and corona discharge properties must be taken into account. In order to reduce the cooling unevenness, the placement of corona discharge plates should noticeably be changed even more, but one should remember that it is dangerous to place the corona discharge plates too close to the housing, where the air flow velocity should be faster.

Experimental device measurements are compared with the simulation results. Measurements in 7 positions were made to obtain a credible airflow velocity in the outlet of the device. For each 
measurement, an anemometer covered a particular cross-section area. Fig. 6 shows comparison of the experimental measurements obtained with the simulated airflow velocity in the outlet.

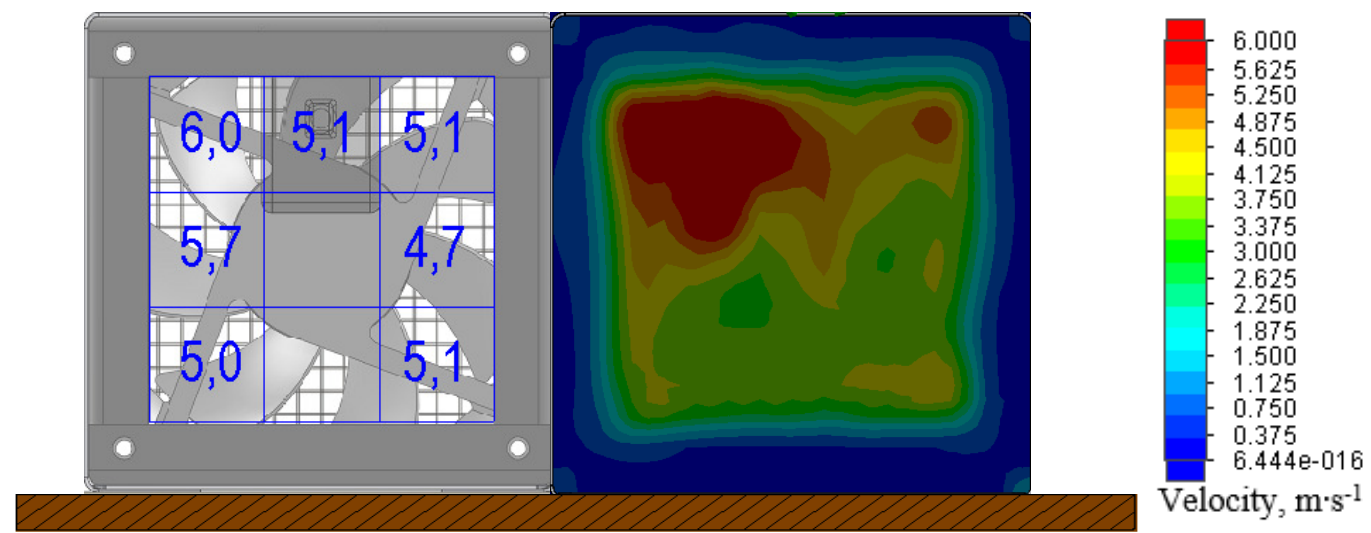

\section{Fig. 6. Comparison of experimental measurement and simulation of air flow velocity}

The highest air flow velocity is observed in the upper left corner because the top part of the frame deflects the air flow. Simulated air flow trajectories and velocity through the section are similar to the experimental measurements. The flow cross-section area $\mathrm{S}=0.0081 \mathrm{~m}^{2}$ in the outlet. Assuming an average flow velocity $v_{\text {avg }}=5.24 \mathrm{~m} \cdot \mathrm{s}^{-1}$ in the ozone generator output, the volume flow rate $\mathrm{Q}$ is calculated:

$$
Q=v_{\text {avg }} \cdot S .
$$

The obtained flow rate $Q=0.0454 \mathrm{~m}^{3} \cdot \mathrm{s}^{-1}$. The simulations showed a volume flow rate $Q_{s i m}=0.0413 \mathrm{~m}^{3} \cdot \mathrm{s}^{-1}$. Coincidence is about $91 \%$. The inaccuracies of the fan model created could affect the simulation results. According to other flow simulation studies with turbulent trajectories, a similar problem is to accurately measure the complicated blade geometry used for the input data [11; 12]. More precise fan model could be obtained by using the high quality $3 \mathrm{D}$ scanner.

Temperatures of ceramic plates could only be measured by the non-contact method due to the high voltage of corona discharge. For each ceramic plate, the maximum heating temperature is measured using an infrared thermometer $42510 \mathrm{~A}$ and the obtained data are compared with the results of simulations in Fig. 7.

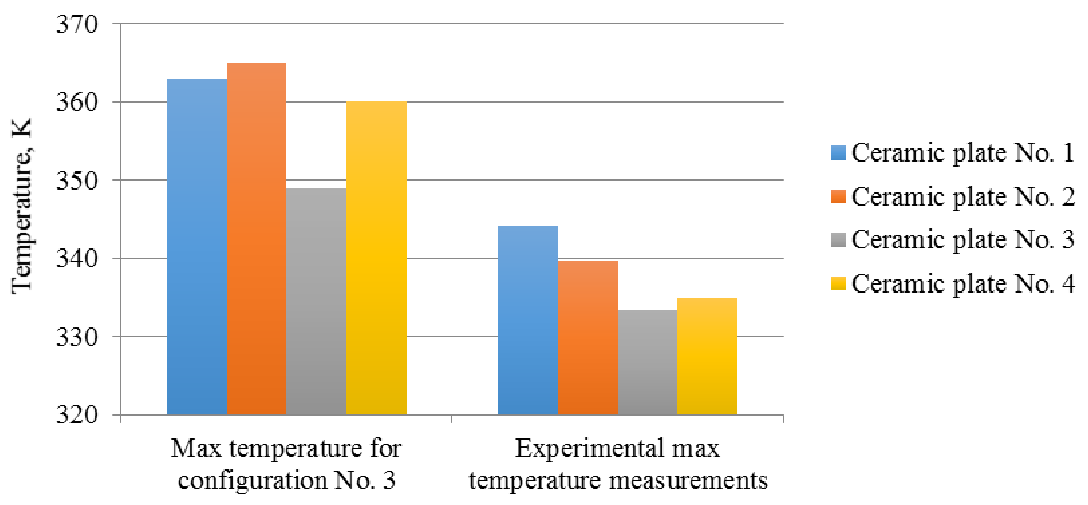

Fig. 7. Simulation and experimental measurement heating temperature comparison

Max temperature of the first ceramic plate differed for only $5 \%$, second about $7 \%$, third $4 \%$ and forth $7 \%$. Temperature measurements differed from the simulations only by $7 \%$ in some areas, but the distribution pattern remained. Thermographic camera should be used to depict the experimental temperature distribution more clearly.

\section{Conclusions}

1. Comparison of the experimental and simulation results showed that the simulated air flow speed is describing the real situation with the experimental flow measurements in the device with $91 \%$ 
coincidence. Temperature measurements differed from the simulations only by $7 \%$ in some areas, but the distribution pattern remained.

2. Studies of the air flow trajectory and speed revealed the tendency of negative intercorrelation of the air flow rate and the surface temperature.

3. Simulation of the air flow and heat transfer method allowed to detect and eliminate the areas with problematic heat transfer in the electrical equipment, thereby greatly saving the time and resources of the equipment design.

4. The results of the simulations given show that SolidWorks flow and heat transfer simulations can be used in the design of small electrical equipment requiring a complex aerodynamic cooling model.

\section{References}

[1] Lee K.D., Kim K.Y. "Shape optimization of a fan-shaped hole to enhance film-cooling effectiveness.” Int. J. Heat Mass Transf., vol. 53, 2010, pp. 2996-3005.

[2] Driss Z., Mlayeh O., Driss D. etc. "Numerical simulation and experimental validation of the turbulent flow around a small incurved Savonius wind rotor." Energy, vol. 74, 2014, pp. 506-517.

[3] Schafrik S., Millar D. L. "Verification of a CFD code use for air flow simulations of fractured and broken rock." Appl. Therm. Eng., Apr. 2015.

[4] Vetus instruments. "Anemometer Instruction manual Model: GM816A." [Online] [22.03.2018]. Available at: http://www.tools.in.th/manual/Manual_GM816A.pdf.

[5] Mitutoyo, "Series 500 Data Sheet." [Online] [26.03.2018]. Available at: https://uk.rsonline.com/web/p/calipers/6534521/.

[6] "Carlo Gavazzi." [Online] [27.03.2018]. Available at: https://www.gavazzionline.com/em17.htm.

[7] Tsui Y. Y., Huang Y. X., Lan C. C. etc. "A study of heat transfer enhancement via corona discharge by using a plate corona electrode," J. Electrostat., vol. 87, 2017, pp. 1-10.

[8] “TM-4010 Instruction Manual." 2 p.

[9] FLIR Systems Inc. "InfraRed Thermometer Manual,”2013, 8 p.

[10] Solidworks Corp. "Solidworks." 2017.

[11] Chen W., Liu S., Gao Y. etc. "Experimental and numerical investigations of indoor air movement distribution with an office ceiling fan," Build. Environ., vol. 130, 2018, pp. 14-26.

[12] Augustyn O. P. H., "Experimental and numerical analysis of axial flow fans," 2013, 123 p. 